\title{
Pre-emergence growth and development in the arctic midge Trichotanypus alaskensis Brundin
}

\author{
Malcolm G. BUTLER, ${ }^{1 *}$ Shane D. BRAEGELMAN ${ }^{2}$ \\ ${ }^{1}$ Department of Biological Sciences, North Dakota State University, PO Box 6050, Fargo ND 58108, USA; ${ }^{2}$ Department of \\ Biological Sciences, Environmental and Conservation Sciences Program, North Dakota State University, PO Box 6050, Fargo ND \\ 58108, USA \\ *Corresponding author: malcolm.butler@ndsu.edu
}

\begin{abstract}
Developing at low mean temperatures, arctic chironomids often have prolonged larval growth yet adult emergence is typically a brief and highly synchronous event. How does a midge population achieve synchronous emergence? Under the Absolute Spring Species Hypothesis (AbSS), adult eclosion by early-emerging species may be synchronized by overwintering as fully mature larvae. Such prepupal larvae would neither feed nor grow after spring thaw, only pupate and emerge. The podonomine Trichotanypus alaskensis Brundin is an abundant midge in tundra ponds on Alaska's Arctic Coastal Plain, and one of the earliest-emerging species in this chironomid-dominated insect community. T. alaskensis is univoltine in these arctic ponds, with most emergence from any one pond occurring within less than a one-week span during late June, typically about three weeks after pond thaw. We evaluated T. alaskensis for conformity to the AbSS model by documenting the overwintering state of this species in a tundra pond near Barrow, Alaska, then monitoring larval growth and development of the population from spring thaw to pupation. Most $T$. alaskensis were immature instar IV larvae when collected in late September of both 2010 and 2011, with 10-30\% still in late instar III. Immediately after pond thaw in 2011, all collected larvae had imaginal disc primordia showing early stages of instar IV development. Within the first two weeks following pond thaw, most larvae had doubled their dry mass and developed into mature (prepupal) final-instar larvae. Highly synchronized emergence by $T$. alaskensis is not a consequence of a population overwintering as fullymature larvae, as per the Absolute Spring Species Hypothesis. Rather, larvae in a given tundra pond appear to develop synchronously throughout the life cycle, including a period of substantial growth and rapid prepupal development between spring thaw and earlysummer emergence.
\end{abstract}

Key words: Podonominae; Chironomidae; Arctic; prepupal development; emergence synchrony; Absolute Spring Species Hypothesis.

Received: June 2018. Accepted: July 2018.

This paper was presented at the 20 $0^{\text {th }}$ International Symposium on Chironomidae, Trento, Italy, 2-8 July 2017. Session: Autecology and Physiology.

\section{INTRODUCTION}

Developmental synchronization is crucial to the reproductive success of many species living in highly seasonal environments (Danks, 2007). Indeed, most animal populations at arctic latitudes restrict reproductive activity to a brief portion of an already short summer (Myers and Pitelka, 1979). Fish-free ponds on the Alaskan Arctic Coastal Plain near Barrow, Alaska host abundant invertebrates, especially larval Chironomidae of over 30 species (Butler et al., 1980; Lougheed et al., 2011). Although these shallow tundra ponds remain ice-free throughout June-Sept most years, insect emergence is largely restricted to a 3-4 week window early in that fourmonth arctic summer (Butler et al., 1980; Braegelman, 2016). This early-summer flux of emerging pond insects to the terrestrial landscape provides a crucial prey resource for insectivorous tundra-nesting birds (Yohannes et al., 2010). In any one pond, each chironomid species completes most of its emergence in a week or less, but taxa are temporally staggered through the emergence season. Ponds can differ in thaw date and thermal regime, broadening the temporal distribution of adult emergence for each species at the landscape scale. The seasonal export of adult midge biomass from Barrow tundra ponds to terrestrial consumers is thus largely comprised of the summation, over about one month, of locally synchronous emergence by some 10-12 larger and/or most abundant midge species (Butler, 1980a; Braegelman, 2016).

To predict how overall insect emergence may respond to a warming arctic climate, we must understand what regulates emergence timing at the species level. The High Arctic lacks day-length cues during the early summer weeks when insect emergence occurs. Empirical evidence 
from studies of arctic chironomid emergence (Danks and Oliver, 1972; Welch, 1973; Butler, 1980a; Braegelman, 2016) implicate temperature as a proximate variable influencing year-to-year and among-habitat variation in emergence timing within species. Emergence phenologies may differ among species in their degree of population synchrony, in the seasonal timing of adult emergence, or both (Butler, 1984), and such differences likely reflect taxon-specific developmental life histories. Studying chironomid emergence in high-latitude ponds at Hazen Camp in the Canadian Arctic $\left(81^{\circ} 49^{\prime} \mathrm{N}\right)$, Danks and Oliver (1972) put forth the "absolute spring species" (AbSS) hypothesis to explain the high synchrony of spring emergence they observed, as a consequence of a life-history strategy where

“... all larvae which emerge in any year overwinter as mature larvae (i.e. larvae in which no further growth is necessary before emergence) and in which there is a 'diapause' at this mature larval stage which prevents premature emergence."

Danks and Oliver focused largely on the synchrony of chironomid emergence in the high arctic ponds at Hazen Camp, reporting (p. 679) “... relatively small (but fairly consistent) differences between species". Danks and Oliver also suggested the AbSS hypothesis might apply to all high-arctic chironomids. However, Welch (1973) noted that life histories of chironomids in Canada's Char Lake, $\left(74^{\circ} 56^{\prime} \mathrm{N}\right)$ did not conform to AbSS predictions. Deep-water chironomid larvae in cold-monomictic Char Lake experience $1-4^{\circ} \mathrm{C}$ temperatures year-round and thus lack the winter diapause required by the AbSS hypothesis.

Butler (1980a) considered the absolute spring species hypothesis of Danks and Oliver (1972) as a potential mechanism for highly synchronous chironomid emergence phenologies he observed in Barrow tundra ponds in the mid-1970s. While technically a "High Arctic" environment, Barrow, Alaska $\left(71^{\circ} 17^{\prime} \mathrm{N}\right)$ is a full $10^{\circ}$ of latitude south of the ponds studied by Danks and Oliver on northern Ellesmere Island. Butler (1980a) concluded that not all Barrow pond midges used the AbSS mechanism to maintain population synchrony during emergence, as larvae of at least one species (called "Tanytarsus inaequalis", subsequently described as Tanytarsus nearcticus Butler) clearly grew, and even molted to the final instar, between pond thaw and subsequent pupation/emergence. Butler (1980a) suggested that the temporal sequence of synchronously emerging chironomid species appearing across a 3-4 week emergence season in Barrow tundra ponds reflected an underlying "continuum of life-history types". Butler further assumed that some, and perhaps most, Barrow pond midges did indeed use the AbSS mechanism to time and synchronize adult eclosion, especially those species emerging earliest in the season.
This study is one effort to explore the "continuum of life history types" proposed by Butler (1980a) for Barrow chironomids. As each midge species in the Barrow tundra ponds shows a consistent phenological position within the emerging insect community, we ask how emergence timing relates to (1) overwintering stage, and (2) preemergence larval and pupal development. Earlier work on the Barrow pond chironomid fauna provided detailed life history information only on a few energetically dominant taxa, including two Chironomus and two Tanytarsus species (Butler, 1980, 1982a, 1982b, 2000). We chose here to study the podonomine midge Trichotanypus alaskensis Brundin, also among the topten Barrow pond chironomid taxa in terms of emerging energy production. Trichotanypus alaskensis seemed the most-likely candidate for an absolute spring species among the Barrow midge taxa, given its synchronous emergence only 3-4 weeks after pond thaw. T. alaskensis is a good model for chironomid life-history analysis because of its abundance in Barrow tundra ponds and ease of collection. As both larvae and pupae are free living (non-tubicolous), all life stages and can be sampled easily with a simple net. If the AbSS hypothesis applied to this species, we expected to find fully mature, prepupal T. alaskensis larvae immediately after pond thaw, followed by pupation and adult emergence without further larval feeding or growth.

\section{METHODS}

The study site is located near Barrow (Utqiagivik), Alaska $\left(71^{\circ} 17^{\prime} 27.5^{\prime \prime} \mathrm{N} 156^{\circ} 47^{\prime} 18.5^{\prime \prime} \mathrm{W}\right)$. Our primary T. alaskensis population for this study occupied a thermokarst-degraded ice-wedge pool behind the laboratory operated by the Barrow Arctic Science Consortium (BASC) that we named South-BASC (hereafter SBASC, $71^{\circ} 19^{\prime} 27.27^{\prime \prime} \mathrm{N}$ and $\left.156^{\circ} 40^{\prime} 38.84^{\prime \prime} \mathrm{W}\right)$. The surface area of SBASC varies greatly across the open-water season, ranging from $>72 \mathrm{~m}^{2}$ at thaw to $\sim 60 \mathrm{~m}^{2}$ in late summer. Emergent Carex aquatilis Wahlenberg and Arctophila fulva (Trin.) Andersson ring the pond margins, which drop abruptly to $\sim 50 \mathrm{~cm}$ depth. HOBO underwater loggers recorded hourly water temperatures in SBASC and several other nearby tundra ponds. We collected T. alaskensis by sweeping through the emergent vegetation with a $15 \mathrm{~cm}$ diameter, $100 \mu \mathrm{m}$ mesh dip net, sampling SBASC shortly before pond freeze on two autumn dates (30 Sept in both 2010 and 2011), and throughout June 2011. After pond thaw in early June 2011 (approximately 6 June), we sampled every 3 days (rarely 2 or 4 days) until no larvae or pupae of $T$. alaskensis were found. An attempt to collect overwintering larvae in mid-October 2012 was unsuccessful, as we were unable to find any T. alaskensis 
larvae after searching under $10 \mathrm{~cm}$ of ice cover at multiple locations in SBASC and four other Barrow ponds.

After an early snowfall on 30 September 2010, we collected $T$. alaskensis larvae by sweeping vegetation beneath the floating slush. We then took digital photographs of the live larvae at 70X under a dissecting microscope, and used the software ImageJ to measure larval head capsule width (HCW) in $\mathrm{mm}$, across the widest part of the head capsule in a dorsal or ventral view. Once photographed, we dried all 46 larvae for at least $24 \mathrm{~h}$ at $60^{\circ} \mathrm{C}$ and weighed each to the nearest $1 \mu \mathrm{g}$ on a Cahn electrobalance.

We used similar procedures for larval samples collected in 2011, but preserved all larvae immediately upon collection. On all but one sampling date in 2011, we immediately fixed collected larvae in Kahle's fluid (15 parts ethanol, 5 parts concentrated formaldehyde solution, 1 part glacial acetic acid, 30 parts distilled water), as this fixative best preserves the imaginal discs of late-instar larvae needed for determination of developmental phase and larval sex. As no Kahle's fluid was available on 13 June, we used $2.5 \%$ formalin to fix the sample collected on that date.

We tested for significant larval growth between two dates by comparing dry weights of larvae in sequential samples with Student's $t$-test, after confirming normality and equality of variance.

We used HCW to score all larvae (from live photos in 2010 , or preserved in 2011) for larval instar. We also scored the developmental progress of each instar IV larva toward pupation, based on photographs of thoracic primordia (imaginal discs of respiratory organ, wing, haltere, and legs) visible in final instar larvae, based on "developmental phases" similar those established for instar IV Chironomus (Wülker and Götz, 1968; Ineichen et al., 1983; Goddeeris et al., 2001). The nine developmental phases first described by Wülker and Götz represent equal intervals of development under constant, optimal laboratory conditions. The forms taken by these imaginal discs in Trichotanypus differ somewhat from those of Chironomus, thus we developed a unique set of developmental criteria to place T. alaskensis larvae with visible thoracic primordia into nine developmental phases approximately analogous to those created for Chironomus.

We sexed preserved larvae by viewing genital primordia developing in abdominal segments 8 and 9 (Wülker and Götz, 1968). When pupae or pupal exuviae appeared in the samples, we scored the population for the relative proportions of larvae, pupae, and eclosed adults.

\section{RESULTS}

We collected a total of 293 T. alaskensis larvae on eight dates from late September 2010 through late Sept
2011. All larvae collected in June 2011 were instar IV, with varying degrees of imaginal disc development visible in thoracic segments. By ranking larval images from least mature to most mature, we established a nine-phase developmental gradient for scoring the relative maturity of instar IV larvae.

We describe thoracic features of Trichotanypus developmental phases 2, 4, 6, and 8 below; one can extrapolate or interpolate other phases based on the size and shape of imaginal discs in the even-numbered phases illustrated in Fig. 1.

Phase 2: Head capsule now fully sclerotized (having been clear or lightly pigmented early in phase 1 , following molt from instar III). Leg primordia $\left(\mathrm{L}_{1}, \mathrm{~L}_{2}, \mathrm{~L}_{3}\right)$ appear as small circular discs in all thoracic segments, but without well-defined leg sheaths. Wing (W) and haltere $(\mathrm{H})$ primordia are present in segments 2 and 3, and are similar in size and appearance to the leg discs. Primordia occupy at most $50 \%$ of the vertical width of segments 2 and 3 in lateral view. Respiratory organ (RO) evident as small disc in posterior-dorsal corner of segment $1,<1 / 2$ the diameter of leg disc.

Phase 4: Leg sheaths and early leg segmentation become visible, most discernably in segment 2 . Wing disk in segment 2 becomes more polygonal, less circular than in phase 2. Haltere in segment 3 is quadrate to oval, with tip descending posterior to $\mathrm{L}_{3}$. Wing and leg primordia occupy $>70 \%$ of vertical width in segment 2 ; haltere and leg primordia occupy $>50 \%$ of vertical width in segment 3. RO is clearly evident in segment 1 ; space between RO and leg disk equals or exceeds RO diameter.

Phase 6: Wing definition continues in segment 2, wing disk becoming more polygonal with tip extending posterior-ventrally to mid-point of leg disk. Haltere in segment 3 narrowly triangular, with acute tip descending behind upper 1/3-1/2 of leg disc. Leg segments well defined in all segments, $\mathrm{L}_{2}$ and $\mathrm{L}_{3}$ remain well separated. Primordia occupy $>80 \%$ of vertical width in segment 2 and $>70 \%$ in segment 3 . RO a well-defined oval disc in segment 1, still dorsal/posterior to leg disc. Segments 2 and 3 begin to fuse, but only moderately swollen.

Phase 8: Segments 2 and 3 completely fused and swollen. Imaginal discs occupy nearly entire lateral view, with wing broadly meeting both $\mathrm{L}_{2}$ and $\mathrm{L}_{3}$. $\mathrm{RO}$ extends anteriorly above $\mathrm{L}_{1}$.

Of the 46 larvae collected on 30 September 2010, only $5(\sim 10 \%)$ were instar III, with HCWs ranging 0.23-0.29 $\mathrm{mm}$. The 41 larger larvae, with $\mathrm{HCW}$ values averaging 0.35 $\mathrm{mm}$ (range: 0.31-0.39 $\mathrm{mm}$ ), all showed imaginal disk primordia and thus were considered instar IV. One year later (30 September 2011), eight of the 27 larvae collected $(\sim 30 \%)$ were instar III, with the majority in instar IV. Our first population sample immediately following pond thaw in 2011 (collected on 7 June) contained no instar III larvae, 

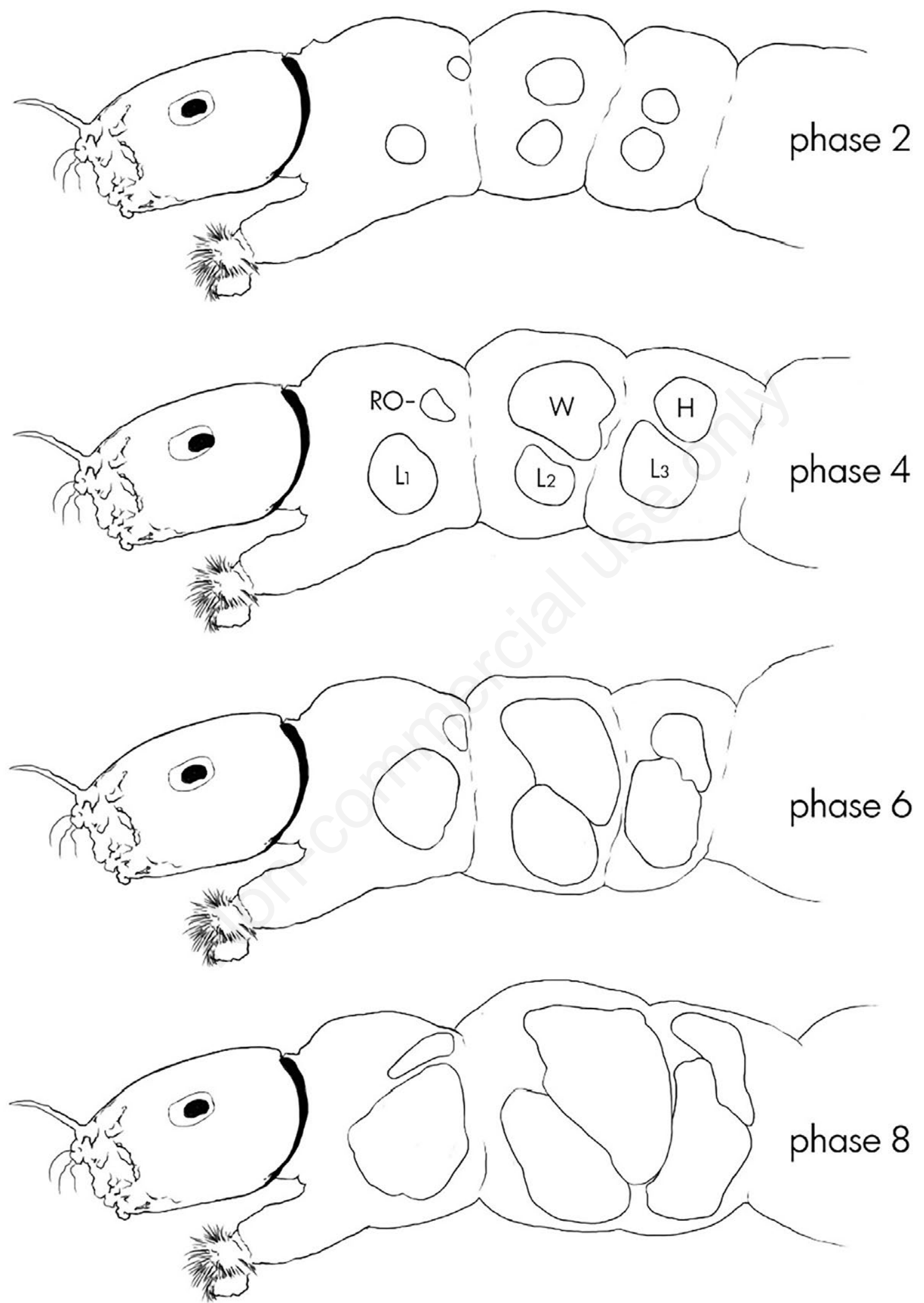

Fig. 1. Head and thorax of late-instar Trichotanypus alaskensis larvae, showing size and shape of developing pupal/imaginal disk primordia characterizing four of nine developmental phases. See text for additional details. RO, developing respiratory organ; L1, L2, L3, leg primordia in each thoracic segment; W, wing primordia; $H$, haltere primordia. 
despite having over 3-fold as many individuals as the late Sept 2010 sample about 2 wks before pond freeze-up.

The pond was covered by $10 \mathrm{~cm}$ of snow-slush when larvae were collected on 30 September 2010, and water temperature remained below $1^{\circ} \mathrm{C}$ until the sediments froze in October. We did not directly observe pond thaw in 2011, but snow/ice conditions in the pond vicinity on 7 June and temperature data from an overwintering logger in an adjacent tundra pool suggest that SBASC had thawed and larvae were potentially active a maximum of 1-2 days prior to our first 2011 sample. The lack of any instar III larvae in the 7 June sample suggests continued development and molting of these $T$. alaskensis larvae prior to complete freezing of the pond and its sediments in mid-October, a period when water temperature remained $<1^{\circ} \mathrm{C}$.

On 7 June 2011, mean larval dry weight was $0.12 \mathrm{mg}$, a $14 \%$ increase over the $0.10 \mathrm{mg}$ mean dry weight of larvae in September 2010 (Fig. 2, $t$-test, $\mathrm{P}=0.04$ ). In the 10 June sample, mean larval dry mass was unchanged at $0.12 \mathrm{mg}$, indicating no detectable larval growth since 7 June (Fig. 2, $t$-test, $\mathrm{P}=0.28$ ). A logger was not placed in Pond SBASC until 13 June 2011, but temperatures in similar adjacent pools oscillated between $1^{\circ} \mathrm{C}-5^{\circ} \mathrm{C}$ during that 3 day period. Diel temperature oscillations in SBASC ranged between $2^{\circ} \mathrm{C}-9^{\circ} \mathrm{C}$ until 16 June, then between $4^{\circ} \mathrm{C}-15^{\circ} \mathrm{C}$ until 23 June. Larvae gained mass steadily during this period of increasing water temperatures, nearly doubling their overwintering mean dry weight to a peak value of $0.21 \mathrm{mg}$ on 19 June. Sexual dimorphism in larval weight is evident on all June dates, with female dry weight exceeding that of males by 35 $45 \%$ through 16 June when male larval weight peaked. The first pupae appeared on 19 June, and by 23 June the remaining larvae (sexes combined) had lost $15 \%$ of peak larval dry mass. Maturing males lost more weight (19\%) than did females $(8 \%)$ as they approached pupation. We collected a single, phase-9 male larva on 25 June (not shown in Fig. 2), when the remaining T. alaskensis population had either pupated, died, or emerged.

Following pond thaw during the first week of June 2011, all T. alaskensis larvae in samples collected on 7 and 10 June were early in instar IV, with developmental scores lower than phase 5 (Fig. 3). Due to poor sample fixation on 13 June, we could not score developmental phase of larvae collected on that date. By 16 June, the population consisted of larvae distributed across a range of final-instar developmental states, from phase 3 with moderate development of thoracic primordia, to prepupae in phase 9 with notably inflated thoracic segments. Three days later (19 June) over $90 \%$ of all T. alaskensis were phase-9 prepupae, or had already pupated. First emergence of adult $T$. alaskensis appeared in the sample on 23 June in the form of shed pupal exuviae, with most of the population advanced to the pupal stage. Two days later (25 June) a majority of the population had emerged, with some pupae and one prepupal larva still present in the sample.

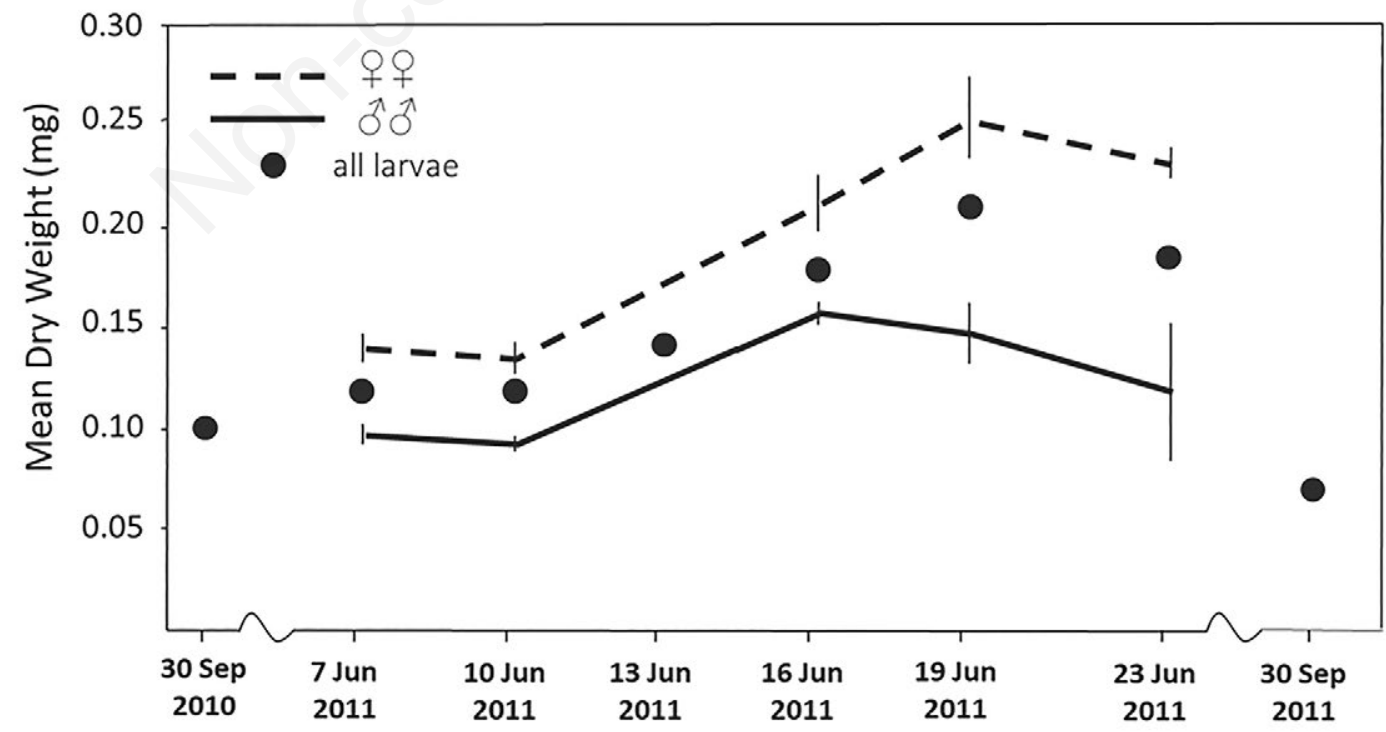

Fig. 2. Mean dry mass of Trichotanypus alaskensis larvae on eight dates from Sept 2010 to Sept 2011, with sex-specific values for male and female larvae collected during June 2011 (vertical bars show \pm 1 standard error). Sex of larvae was not determined in samples collected in September 2010 or 2011, nor on 13 June 2011. See "Results" section for significance tests of changes in mean dry mass between sampling dates. 


\section{DISCUSSION}

From our analysis of larval overwintering and preemergence growth and development by Trichotanypus alaskensis, it is clear that this chironomid fails to meet the "absolute spring species" criteria laid out by Danks and Oliver for high arctic chironomids. First, T. alaskensis larvae in Barrow tundra ponds do not overwinter as "mature larvae ... in which no further growth is necessary before emergence" (Danks and Oliver, 1972). Instead, most if not all larvae overwinter in early instar IV, with possibly a small percentage still in instar III. As we collected no instar III Trichotanypus in our earliest postthaw sample in June 2011, we presume that the few smaller larvae present in late September 2010 (and in 2011) continued to grow and develop, molting to instar IV beneath the developing ice cover prior to pond freezeup in October. Alternatively, such small larvae may have overwintered as instar III and molted to instar IV immediately following spring thaw. We might also simply have missed them in our collection on 7 June. Lackmann and Butler (2018) have subsequently documented overwintering as instar III by a small fraction of T. alaskensis larvae in other Barrow pond populations. As we failed to find any larvae of this species under developing ice cover during a mid-October visit in 2012, we presume overwintering Trichotanypus larvae may migrate to pond perimeters before freezing. Active larvae are evident in the earliest meltwaters when spring thaw begins, and overwintering at pond margins, where meltwater moats typically form, would give T. alaskensis an early start on spring growth and maturation.

Danks and Oliver (1972) defined "mature larvae" as those "ready to pupate without further feeding in spring...i.e. larvae in which no further growth is necessary before emergence". Although we did not investigate larval feeding by this species directly, feeding is clearly required for these T. alaskensis larvae to double their mean dry weight in the 2.5 weeks between pond thaw and pupation. When Braegelman (2016) attempted laboratory rearing of $T$. alaskensis collected at pond thaw, larvae failed to develop until provided with food in the form of particulate detritus.

Characterizing the progress of larval development toward pupation and subsequent emergence requires a more precise terminology than general descriptors like "instar", "mature final instar", or "prepupa". We defined a series of instar IV developmental phases similar to the

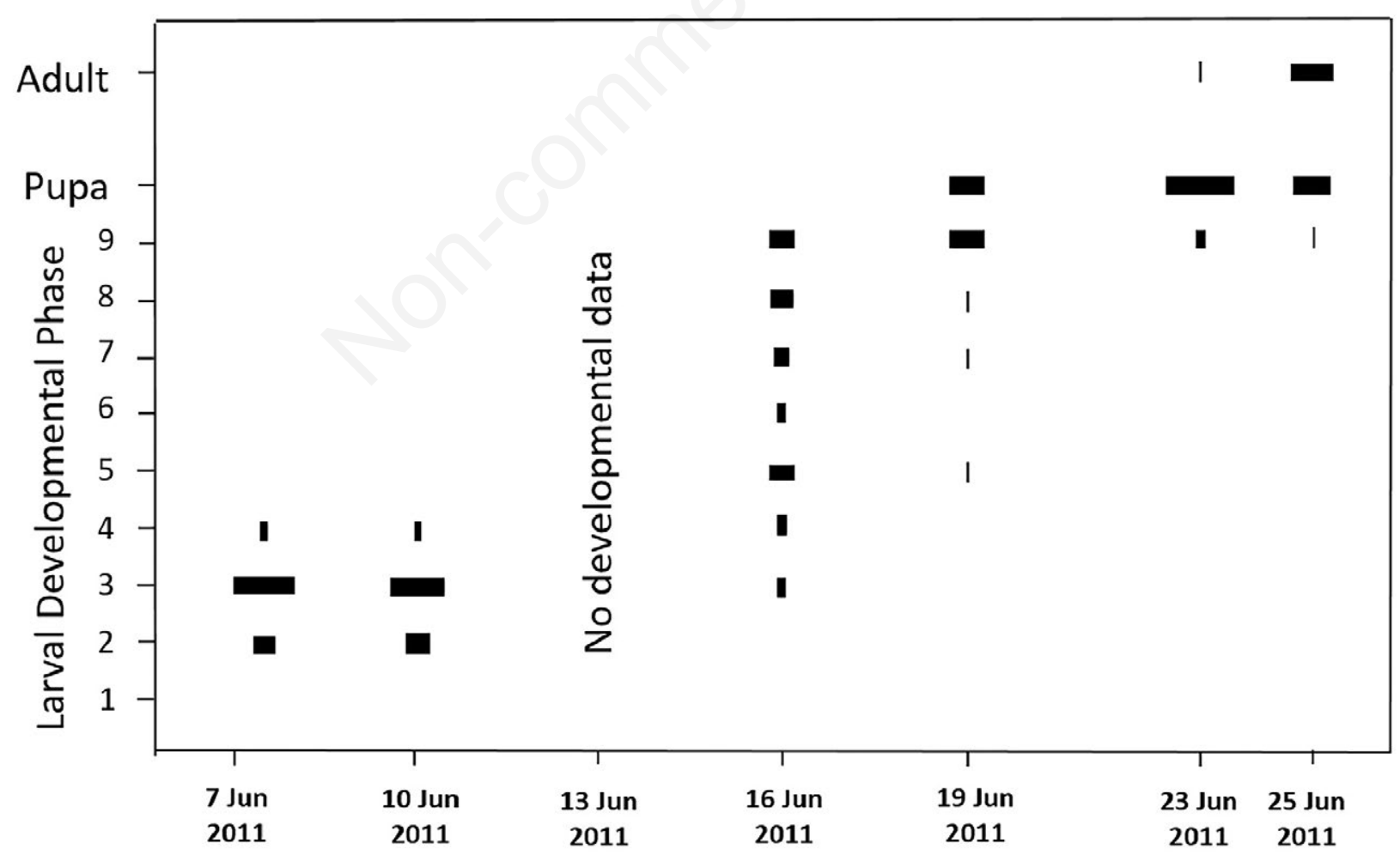

Fig. 3. Percent distribution of Trichotanypus alaskensis life stages in Pond SBASC on six dates during the 2.5 weeks from pond thaw to peak adult emergence. On each sampling date, the population is distributed among nine developmental phases of the final larval instar, followed by pupal and adult stages. Developmental phases of larvae on 13 June were not scored due to poor sample preservation. 
scheme created and widely used for Chironomus (Wülker and Götz, 1968; Ineichen et al. ,1983; Goddeeris et al., 2001), then used this index to track development of the T. alaskensis population in SBASC throughout the postthaw period of larval growth and pre-pupal maturation. The overwintering population consisted of larvae around phase 3, which had progressed about one-third of the way from the instar III-IV molt to pupation and emergence. Larval development did not progress under the low pond temperatures during 7-10 June, as residual bedfast pond ice and snow on the surrounding tundra continued to melt. Lack of developmental phase data on 13 June obscures the exact onset of resumed larval development, but over a period of six days (10-16 June) nearly all larvae showed renewed development, with two-thirds of the population nearing pupation (phases 7-9) in the 16 June sample. Only three days later (19 June) all but a few individuals were either late prepupae (phase 9) or pupae.

Apparent developmental asynchrony of the population on 16 June was ephemeral, for on all other dates most $T$. alaskensis clustered in very similar developmental states. Rapid larval development in midJune occurred during a period of increasing water temperatures, with recorded daily maxima typically $9^{\circ} \mathrm{C}$ $15^{\circ} \mathrm{C}$. With only a single temperature logger in place, it is difficult to characterize the actual temperatures experienced by these vagile larvae that swim throughout the water column and among dense stands of emergent grass and sedge. While only a half-meter deep, SBASC Pond is small and narrow and thus has a high relative depth. On warm, calm days, the top few $\mathrm{cm}$ can stratify at over $20^{\circ} \mathrm{C}$, yet water $<10^{\circ} \mathrm{C}$ can be found deeper, or within emergent vegetation. Such thermal variation among microhabitats may partly explain the apparent lack of developmental synchrony evident on 16 June. Alternatively, both larvae and pupae may be able to regulate their developmental progress by migrating among zones where warmer or cooler temperatures will enhance, or retard, their developmental progress toward pupation or emergence.

Clearly, synchronous emergence by T. alaskensis results not from overwintering as fully-grown, nonfeeding, mature larvae. Rather, there appears to be a general synchronization of population development throughout the univoltine life cycle. Thermal conditions likely regulate the timing of egg eclosion following adult emergence, mating, and ovipostion in late June and early July. Most larvae then grow to early instar IV, with a small fraction remaining in late instar III as the ponds freeze to the permafrost in October. Shortly after spring thaw, once peak diel water temperatures exceed $\sim 5^{\circ} \mathrm{C}$, larvae resume growth and development according to the local thermal regime, which differs from pond to pond more in the timing of thaw than in the overall annual heat budget. T. alaskensis populations in other Barrow ponds follow this same general life-history pattern, with small differences the exact timing of the adult emergence pulse. Tundra ponds at Barrow now thaw in late May or early June, about a week earlier than in the 1970s (Miller et al., 1980; Andresen et al., 2017). Similarly, Trichotanypus emergence now peaks about one week earlier on average, comparing emergence records from the mid-1970s (Butler, 1980a) with data from 2009-2013 (Braegelman, 2016).

Among these Barrow midge species, the degree of population synchrony in adult emergence seems unrelated to the seasonal timing of a species' emergence. In proposing their absolute spring species hypothesis, Danks and Oliver (1972) focused on the high withinpopulation synchrony of adult emergence they observed for chironomids emerging from ponds in the Canadian High Arctic, but characterized differences among species at Hazen Camp as "small but consistent". Pond chironomids at Barrow exhibit levels of emergence synchronization similar to that reported in Canadian High Arctic ponds (Oliver, 1968; Butler, 1980a), yet different midge species at Barrow emerge at consistently different times during an overall emergence season lasting 3-4 weeks. Late-emerging species at Barrow show no less synchronization than the earliest emerging taxa, when one accounts for parasitized individuals with delayed emergence (Butler, 1980a). The highly abundant chironomid Tanytarsus nearcticus Butler is the latestemerging species at Barrow, both now and over four decades ago. Reported as Tanytarsus inaequalis by Butler (1980a), and Tanytarsus sp.2 by Butler (1980b), this semivoltine species overwinters twice. At the end of their first summer larvae freeze as instar II, then grow through a full second summer to reach instar III. In the spring of the year in which they will emerge, larvae thaw as instar III, soon molt to instar IV, then more than double their mass prior to pupation and emergence in late July (Butler, 1980b). This life history is remarkably similar to that of Trichotanypus alaskensis, but for two salient differences: Tanytarsus nearcticus requires two years of larval growth and development and emerges late in the season, whereas Trichotanypus alaskensis is univoltine and emerges very early in the summer. Neither midge uses the absolute spring species mechanism for emergence synchronization. We can now question whether any chironomids at Barrow actually meet the AbSS criteria. Detailed life history analyses are required to determine the overwintering states and pre-emergence patterns of larval development needed to address this question. Understanding environmental controls of life history scheduling is crucial to predicting how a changing arctic climate may alter seasonal patterns of insect emergence, upon which many arctic insectivores rely. 


\section{CONCLUSIONS}

Trichotanypus alaskensis is an abundant, earlyemerging chironomid in coastal tundra ponds on the Alaskan Arctic Coastal Plain. Studying this species in tundra ponds near Barrow, Alaska, we analyzed larval overwintering states and post-thaw patterns of larval growth and development leading to pupation and adult emergence in early summer. We conclude that this species does not use the hypothesized "absolute spring species" mechanism to synchronize adult emergence. Instead, high emergence synchrony of this midge, and perhaps other arctic chironomids, may simply reflect uniform development rates within larval populations that experience cold, but consistent thermal conditions in their arctic pond habitats.

\section{ACKNOWLEDGMENTS}

This work was completed at North Dakota State University (NDSU), USA as part of a doctoral dissertation by SDB. The North Slope Borough and the Ukpeagvik Inupiat Corporation permitted access to the field site.

We thank Eric J. Herman for assistance in the field and lab, and Todd L. Sformo for collecting larvae in September 2011. Daniel C. McEwen and Alec R. Lackmann provided helpful discussion and advice. Ewelina Bielak-Lackmann prepared the illustrations for Fig. 1.

We gratefully acknowledge financial support from the U.S. Arctic Landscape Conservation Cooperative, the U.S. National Fish and Wildlife Foundation, and the Environmental and Conservation Sciences Program at NDSU.

\section{REFERENCES}

Andresen CG, Lara MJ, Tweedie CE, and Lougheed VL, 2017. Rising plant-mediated methane emissions from arctic wetlands. Global Change Biol. 23:1128-1139.

Braegelman SD, 2016. Seasonality of some arctic Alaskan chironomids (Order No. 10147072). Available from Dissertations \& Theses @ North Dakota State University; ProQuest Dissertations \& Theses Global. (1830464132).

Butler MG, 1980a. Emergence phenologies of some arctic Alaskan Chironomidae, p. 307-314. In: D.A. Murray (ed.), Chironomidae: Ecology, systematics, cytology, and physiology. Pergamon Press, Oxford.

Butler MG, 1980b. Population ecology of some arctic Alaskan
Chironomidae (Diptera). Ph.D Thesis, University of Michigan, USA.

Butler MG, 1982a. A seven-year life cycle for two Chironomus species in arctic Alaskan tundra ponds (Diptera:Chironomidae). Can. J. Zool. 60:58-70.

Butler MG, 1982b. Production dynamics of some arctic Chironomus larvae. Limnol. Oceanogr. 27:728-736.

Butler MG, 1984. Life histories of aquatic insects, p. 24-55. In: V.H. Resh and D.M. Rosenberg (eds.), The ecology of aquatic insects. Praeger.

Butler MG, 2000. Tanytarsus aquavolans, spec. nov. and Tanytarsus nearcticus spec. nov., two surface-swarming midges from arctic tundra ponds. Spixiana 23:211-218.

Butler MG, Miller MC, Mozley SC, 1980. Macrobenthos, p. 297-339. In: J.E. Hobbie (ed.), Limnology of tundra ponds, Barrow, Alaska. Dowden, Hutchinson and Ross.

Danks HV, 2007. The elements of seasonal adaptations in insects. Can. Entomol. 139:1-44.

Danks HV, Oliver DR, 1972. Seasonal emergence of some high arctic Chironomidae (Diptera). Can. Entomol. 104:661-686.

Goddeeris BR, Vermeulen AC, De Geest E, Jacobs H, Baert B, Ollevier F, 2001. Diapause induction in the third and fourth instar of Chironomus riparius (Diptera) from Belgian lowland brooks. Arch. Hydrobiol. 150:307-327.

Ineichen H, Meyer B, Lezzi M, 1983. Determination of the developmental stage of living fourth instar larvae of Chironomus tentans. Develop. Biol. 98: 278-286.

Lackmann AR, Butler MG, (2018). Breaking the rule: Five larval instars in the podonomine midge Trichotanypus alaskensis Brundin from Barrow, Alaska. J. Limnol. 2018;77(s1). (in press).

Lougheed VL, Butler MG, McEwen DC, Hobbie JE, 2011. Changes in tundra pond limnology: re-sampling Alaskan ponds after 40 years. Ambio 40:589-599.

Miller MC, Prentki RT, Barsdate RJ, 1980. Physics, p. 51-75 In: J.E. Hobbie (ed.), Limnology of tundra ponds, Barrow, Alaska. Dowden, Hutchinson \& Ross.

Myers JP, Pitelka FA, 1979. Variations in summer temperature patterns near Barrow, Alaska: analysis and ecological interpretation. Arct. Alp. Res. 11:131-144.

Oliver DR, 1968. Adaptations of arctic Chironomidae. Ann. Zool. Fenn. 5: 111-118.

Welch HE, 1973. Emergence of Chironomidae (Diptera) from Char Lake, Resolute, Northwest Territories. Can. J. Zool. 51:1113-1123.

Wülker W, Götz P, 1968. [Die Verwendung der Imaginalscheiben zur Bestimmung des Entwicklungszustandes von Chironomus-Larven (Dipt.)]. [Article in German]. Z. Morphol. Tiere 62:363-388.

Yohannes E, Valcu M, Lee RW, Kempenaers B, 2010. Resource use for reproduction depends on spring arrival time and wintering area in an arctic breeding shorebird. J. Avian Biol. 41:580-590. 